\title{
Metrological changes in the surface morphology of cereal grains in the mixing process
}

\author{
Jolanta B. Królczyk \\ Opole University of Technology, Prószkowska 76, 45-758 Opole, Poland
}

Received November 15, 2015; accepted May 4, 2016

\begin{abstract}
A b s t r a c t. The paper presents a new idea of approach to the analysis of surface morphology of cereal grains. In this paper, the surfaces of maize were analyzed using an optical 3D measurement system to determine the surface morphology and parameters of surface topography. It was established how changes in the moisture influence on the surface characteristics. Comprehensive parametric analysis was conducted for maize grains with different moisture contents. The objective of this study was to comprehensively characterize the surface morphology of maize in contact area using standardized 3D roughness parameters as well as other characteristics such as structure direction and isotropy. This is the first study that has presented, elucidated, and discussed the relationships between some morphological parameters of cereal grains. This research contributes to better understanding of the mixing process. The main findings are: the values of roughness parameters kurtosis and skewness are characterized by higher values for maize grains with lower moisture, compared with maize grains with higher moisture content; there is a close relationship between the maize grain moisture content and the surface roughness parameters of kurtosis and skewness; maize grains have an anisotropic structure.
\end{abstract}

$\mathrm{K}$ e y w o r d s: cereal grains, moisture, maize grains, surface morphology, surface topography

\section{INTRODUCTION}

The mixing process is a particular unit operation, which occurs in a great number of practical applications and in every processing industry such as mining, pharmaceuticals, energy, food, and agriculture (Cleary and Sinnott, 2008; Mehta, 2012; Wiacek and Molenda, 2011). The effect of mixing determines the quality of products. It is a complex process dependent on a number of parameters such as the characteristics of mixed materials (Bridgwater, 2012;

*Corresponding author e-mail: j.krolczyk@po.opole.pl
Chaudhuri et al., 2006; Doucet et al., 2008; Królczyk and Tukiendorf 2008; Yang, 2006), the mixing device type and, conditions for carrying out the process (Boss, 1987; Cleary and Sinnott, 2008; Pöschel and Schwager, 2010; Wornyoh et al., 2007).

The properties of particles include many aspects such as the grain size, shape and surface characteristic, mass and bulk density, moisture content and how it is bound, internal friction coefficient, flowability, angle of repose, embrittlement and brittleness, the ability of grain to agglomerate, and the tendency to bond with other grains (cohesion) (Bridgwater, 2012; Chaudhuri et al., 2006; Doucet et al., 2008; Królczyk and Tukiendorf, 2008; Yang, 2006). Furthermore, other parameters, such as the dimensions and shape of the mixer, dimensions and shape of the agitator, construction materials and machining of workpiece and the type, number, and placement of equipment for loading and emptying the mixer, the mass and volume shares of mixing particles, the ratio of the mixture volume to the mixer operating capacity, the way and the order of addition of components of the mixture, and the intensity of the mixture, influence the course of the mixing process and the quality of the products obtained. In previous research performed by the author (Królczyk, 2013), it was noted that a longer time of mixing adversely affects the quality of the mixture in terms of the quantity of contaminants in the final product. It was summarized that contaminants ie wastes generated during mixing, come from the vibrating screen, swarf and dust collection systems, and cyclones; thus, they are present in the final product. They constitute nearly $1 \%$ of the mass of raw materials used for production. The quantity 
of contaminants obtained depends on many factors, including the formula and parameters of mixed components, such as moisture. During the mixing process performed in the mixer, the processes of crushing, breaking, and abrasion of seeds occur, which is caused by friction processes arising between grains. It was determined that the highest share of contaminants for a 14-component mixture comes from the final product and amounts to $62.78 \%$, compared with other contaminants. During mixing, seeds are not arranged randomly, but they indicate certain directivity. Surface features will determine, inter alia, the quantity of wastes produced in the mixing process.

The mixing process is a result of mechanisms like diffusion, convection, and shear (Bridgwater, 2012; Laurent et al., 2002). In industrial applications, growing quantities of raw materials are being used in the form of granular materials, and an increasing number of products are manufactured in such a form.

In the literature covering the research, one fundamental assumption is made that the process of mixing of particulate materials is a random process, wherein components in the mixer are dispersed by chaotic and random motion of the particles (Boss, 1987). This statement is true; however, at the microscale, many dependencies and behavioural conditions of the grains with respect to each other are observed. These conditions depend, among others, on the features of the surface being in contact with grains. Surfaces morphologies are characterized by more or less privileged directions due to the internal structure of material and process orientation. Surface morphology is the result of interactions of cooperating surfaces, which can be represented as threedimensional contact. These phenomena and dependencies should be observed in 3D space, because they reflect interactions between grains occurring in real conditions. Thus, a description of surfaces using only $2 \mathrm{D}$ parameters is insufficient. A three-dimensional surface cannot be sufficiently characterized by a two-dimensional image.

According to Zięba (2001), the complexity of biological systems requires application of more advanced axioms needed to describe them. Such types of systems are treated as open by the author, who believes that the knowledge about them is an evolutionary process.

The use of modern optical devices allows extension of the knowledge regarding the interaction between particles (Mathia et al., 2011; Wieczorowski, 2001). Optical devices are not the only tools that contribute to the development of the knowledge in this field; computer simulations serve the same function. Such simulations are the most significant methods for theoretical investigation of granular materials and provide tools that have facilitated a great part of the expanding research in engineering and physics (Cleary and Sinnott, 2008; Pöschel and Schwager, 2010).

The objective of this study was to comprehensively characterize the surface morphology of maize in contact area using standardized $3 \mathrm{D}$ roughness parameters as well as other characteristics such as structure direction and isotropy. This is the first study that has presented, elucidated, and discussed the relationships between some morphological parameters of cereal grains. This research contributes to better understanding of the mixing process, allows simulation of modelling the operating processes and optimization thereof, and selection of proper parameters of various technological processes.

The existing research studies concerning the morphology of cereal grains cover mainly the issues of the mechanics of granular materials and tribology. However, there are no scientific studies covering determination of functional surface parameters. This article presents these issues for the first time.

Granular plant materials include seed beds of arable crops belonging to a wider category of loose materials. Due to the characteristic effects, including static friction, inelastic collisions, and practically zero energy of thermal movements, they are often considered as a separate state of aggregation. The behaviour of such material is a sum of many well-known effects and other relationships that have not yet been recognised (Horabik and Molenda, 2002). The phenomena occurring between particular elements of the bed are still little known (Frączek and Wróbel, 2003).

Morphological and physical states of plant materials determine the selection of appropriate parameters for many technological processes. A detailed description of this state helps in modelling and optimization of the operating process. Methods for measuring the physical properties of granular plant materials cannot be derived directly from physics, materials science, and structural material strength (Frączek et al., 2003). Features of cereal grains are determined by, among others, the shape, internal structure, and anisotropy of the material, which is characterized by timedependent variability in the structures, due to the fact that it is a live biological material. These materials can be distinguished by deformability under loading and a strong influence of moisture on mechanical properties. The mechanical properties of this group of particulate materials are used as material parameters for the design of machinery, devices, and technologies, control parameters of storage and processing processes, and quality indicators of raw materials and products (Molenda, 2009). In the study by Fracczek et al. (2003), the authors attempted to analyse the methods for measuring selected physical and mechanical properties of granular plant materials.

A comparison of research methods for determination of the strength of a single seed, the relationship between the modulus of elasticity and single seed hardness, measurement of the seed contact surface with a flat surface was performed, and selected mechanical properties of granular plant materials, such as density, shear strength, tension at rest ratio, pressure ratio, uniaxial compressive strength, and elasticity were characterized. Wiącek et al. (2011) presented the current state of study of mechanical properties of 
granular solids with a special focus on agro and food biologically based granular materials. They described, among others, issues related to the mechanics of granular media a continuum approach; geometric structure of granular medium; laboratory testing of mechanical properties including density of granular materials, compressibility and elasticity, strength parameters, coefficient of friction, pressure ratio; indices of strength and flowability used by process technology; and the discrete element method and DEM modelling of mechanical behaviour of grains and seeds. It should be emphasized that extensive research has been undertaken in recent years to correlate the investigations on microstructure with description of macroscopic properties. Facing the doubts about applications of theories based on the elements of continuum mechanics, the research has been focused on analysis of the microstructure. At the base lies the main assumption that the behaviour of the entire medium is determined by the properties of individual grains and by the relationships between adjacent seeds being in contact. In the case of plant materials, it is important to take into account the high deformability of individual seeds, which causes that under pressure the points of contact with seeds turn into surfaces of contact (Frączek and Ślipek, 2006; Wiącek et al., 2011). A literature review indicates that virtual modelling is currently one of the fastest growing trends in modelling plant granular materials (Mabille and Abecassis, 2003). There is no research using the DEM method (Boac et al., 2010; Wojtkowski et al., 2010).

The research of the surface properties of particles regards the inter-particle friction as an obvious component of shear strength (Wiącek et al., 2011). Analysis of force distributions in three-dimensional granular assemblies performed by Blair et al. (2001) reported the significance of inter-particle friction. The study has shown that particle deformation is the key factor for intergranular force distribution. The results show that the phenomenon of internal friction still remains far from a conclusive description (Blair et al., 2001).
The shape, size, and roughness of seeds influence the pressure ratio. The rougher the surface, the higher the angle of internal friction is and, consequently, the lower the pressure ratio (Wiącek et al., 2011). According to Wiącek et al. (2011), it is difficult to separate the influence of the shape and roughness of grains. The authors claimed that it is much easier to observe a combined effect of both factors: the smoother the surface and the closer the shape to a sphere, the higher the pressure ratio. The pressure ratio of material composed of elongated grains, e.g. cereal grain, is generally lower than the pressure ratio of material composed of spherical grains. The shape of the grain results in different distribution of contact points in the material bedding.

\section{MATERIALS AND METHODS}

The authors previous research on the aspects of mixing heterogeneous and multi-component granular materials prompted to formulate a hypothesis that mixing cereal grains does not consists in random and chaotic movement of grains and the mixing process is influenced by multiple factors (Królczyk, 2013; Królczyk, 2014a; Królczyk and Tukiendorf, 2005).

So far, the author has analyzed the mixing process in a 'macro' context, such as aspects for the assessment of mixing process quality (homogeneity), effects of the manner of administration of components into the mixer, kinetics, quantity of contaminants formed in the mixing process, determination of the size of the sample needed to assess homogeneity, the effect of time on the homogeneity, and aspects of abrasive wear of a worm agitator. This research was conducted using an industrial feed mixer shown in Fig. 1. An accurate description, dimensions, and parameters of the mixer and the formula of the mixed granular systems are given in other papers (Królczyk, 2014a; 2014b). An explanatory picture presenting the mixed components is shown in Fig. 1, and examples of formulas are presented in other publications (Królczyk, 2013; 2014a). These studies were performed under industrial conditions.

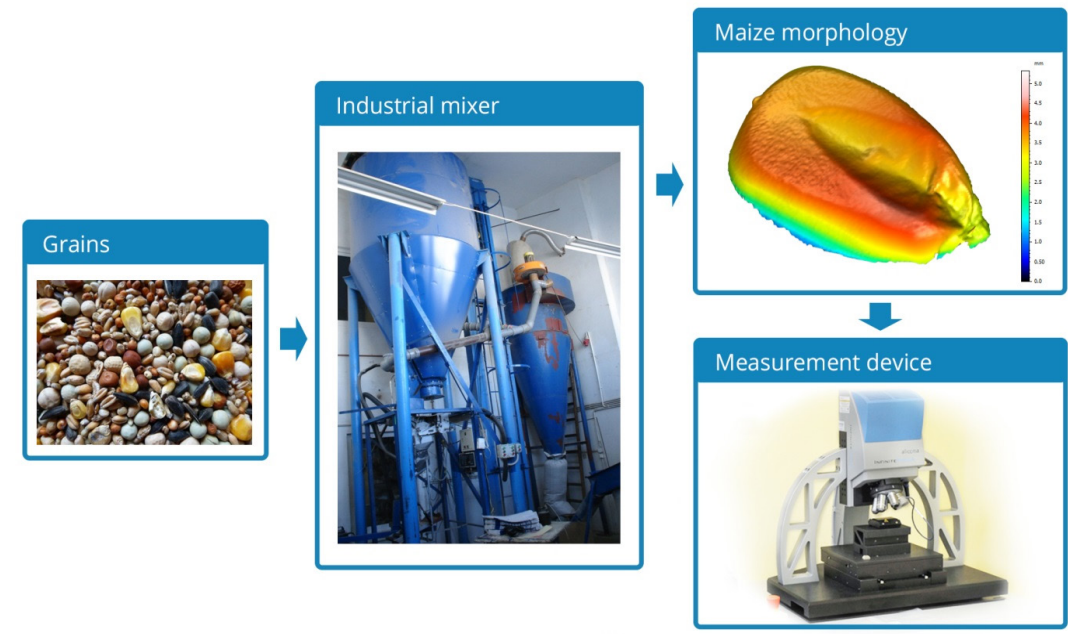

Fig. 1. Schematic diagram of experimental arrangement. 
The multidimensionality of the phenomenon of mixing and the impact of various parameters on the process prompted the author to undertake research on the 'micro' scale, in the context of surface features affecting the mixing process. Therefore, the article presents a selected component of the analyzed granular mixtures - the maize. This grain is one of the most important and widely grown grains in the world. The first experiment presented parameters of the surface of maize grains with a moisture content of $11.1 \%$, which was present in the mixing process shown in Fig. 1 (in the paper, the grain was labelled as 'maize 1'), while the grain from the second tested specimen did not undergo the mixing process, and its moisture content was $40.2 \%$. Grain ' 1 ' with $11.1 \%$ moisture represented a raw material used in technological processes such as mixing. The water content is reduced through drying. The purpose of reduction of the moisture content is to produce safe feed and food (reduce biological processes occurring in grains and prevent microbiological hazards). The other grain with the moisture content $40.2 \%$ was analyzed after the harvest and represented 'wet' grain before technological processes such as drying, transport, storage, and mixing.
Surface morphology analysis was performed using an Infinite Focus Measurement Machine (IFM). The IFM is an optical 3D measurement device, which allows acquisition of datasets at a high depth of focus. The IFM method allows taking images with a lateral resolution down to $400 \mathrm{~nm}$ and a vertical resolution down to $20 \mathrm{~nm}$. The MountainsMap 7.0 software version was used to collect and present the measurement data. The surface morphology analysis was carried out in the OUTech Surface Integrity Lab. The temperature in the measurement laboratory was stable and amounted to $20^{\circ} \mathrm{C}$. A polarizing filter was used in the measurement. Each side of the maize grain was performed by 'stitching'. The results were compared in three large analysis groups, presented in Figs 2-3. Each group contains the following elements:

- selected parameters of the 3D surface topography according to ISO 25178 geometrical product specifications (GPS) - surface texture: areal - Part 2: terms, definitions, and surface texture parameters: $S a$ - average roughness, $S p$ - maximum peak height, $S q$ - root mean square roughness, $S v$ - maximum valley depth, $S z$ - maximum height of surface, $S s k$ - skewness, $S k u$ - kurtosis,

A

\begin{tabular}{|l|r|l|}
\hline \multicolumn{2}{|l|}{ ISO 25178} \\
\hline \multicolumn{2}{|l|}{ Height Parameters } \\
\hline Sq & 36.3 & $\mu \mathrm{m}$ \\
\hline Ssk & 0.252 & \\
\hline Sku & 2.16 & \\
\hline Sp & 91.7 & $\mu \mathrm{m}$ \\
\hline Sv & 92.6 & $\mu \mathrm{m}$ \\
\hline Sz & 184 & $\mu \mathrm{m}$ \\
\hline Sa & 30.8 & $\mu \mathrm{m}$ \\
\hline
\end{tabular}

$\mathrm{mm}$

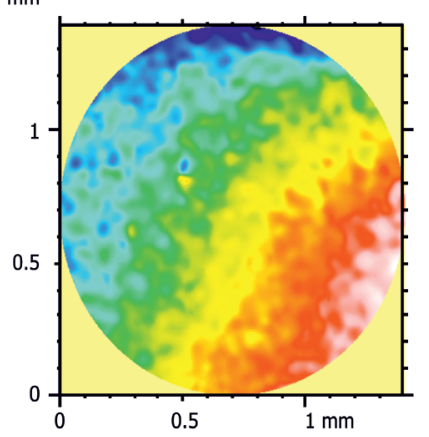

B

\begin{tabular}{|l|r|l|}
\hline \multicolumn{2}{|l|}{ ISO 25178} \\
\hline \multicolumn{2}{|l|}{ Height Parameters } \\
\hline Sq & 74.4 & $\mu \mathrm{m}$ \\
\hline Ssk & -0.0742 & \\
\hline Sku & 1.91 & \\
\hline Sp & 143 & $\mu \mathrm{m}$ \\
\hline Sv & 181 & $\mu \mathrm{m}$ \\
\hline Sz & 325 & $\mu \mathrm{m}$ \\
\hline Sa & 64.1 & $\mu \mathrm{m}$ \\
\hline
\end{tabular}

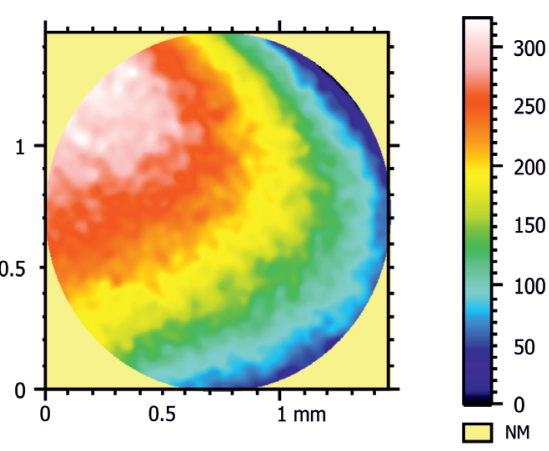

$\mu \mathrm{m}$
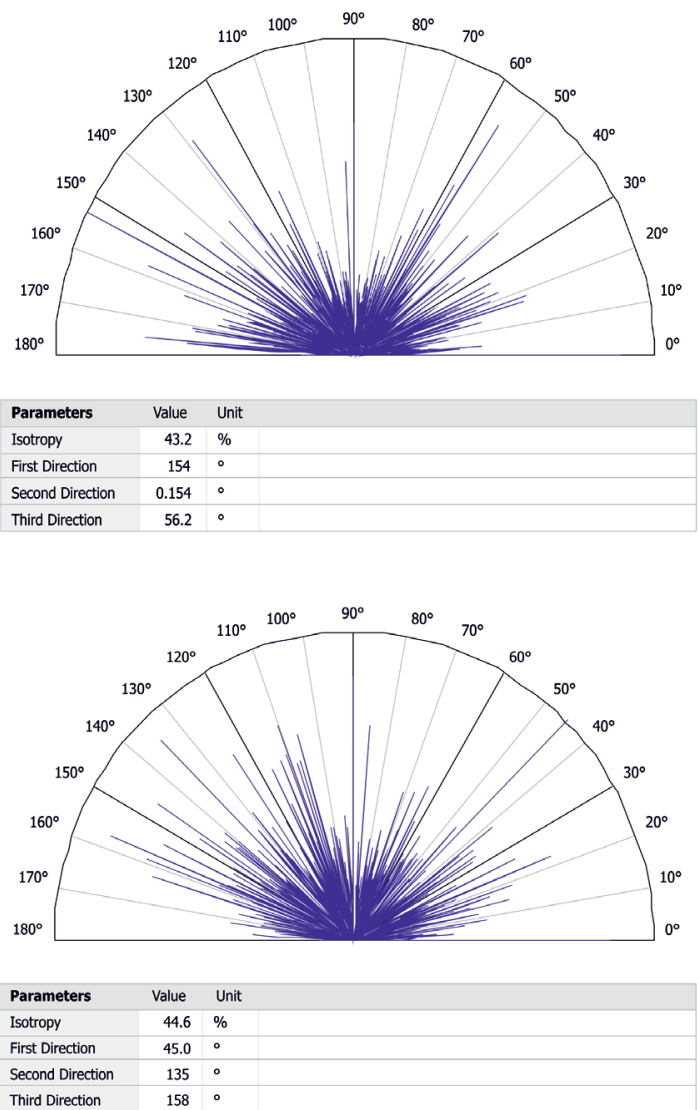

Fig. 2. Surface morphology characterization of 'maize 1' - statistic characteristics, 3D morphological views and polar graph with texture directions for: $\mathrm{A}$ - side ' $\mathrm{a}$ ', position $1, \mathrm{~B}$ - side ' $\mathrm{b}$ ', position 1. 
A

\begin{tabular}{|l|r|l|}
\hline \multicolumn{3}{|l|}{ ISO 25178} \\
\hline \multicolumn{3}{|l|}{ Height Parameters } \\
\hline Sq & 43.9 & $\mu \mathrm{m}$ \\
\hline Ssk & -0.105 & \\
\hline Sku & 2.03 & \\
\hline Sp & 86.7 & $\mu \mathrm{m}$ \\
\hline Sv & 101 & $\mu \mathrm{m}$ \\
\hline Sz & 188 & $\mu \mathrm{m}$ \\
\hline Sa & 37.2 & $\mu \mathrm{m}$ \\
\hline
\end{tabular}
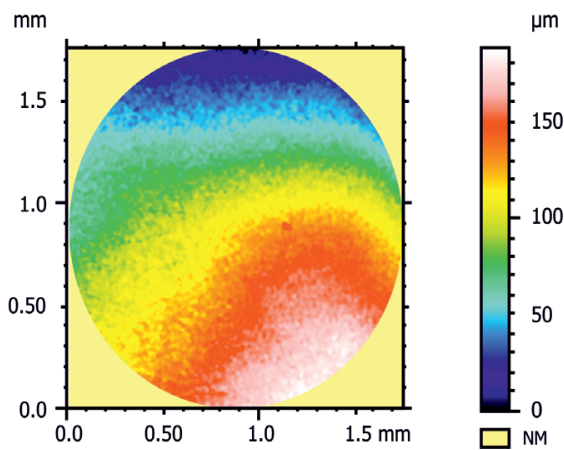

B

\begin{tabular}{|l|r|l|}
\hline \multicolumn{3}{|l|}{ ISO 25178} \\
\hline \multicolumn{3}{l|}{ Height Parameters } \\
\hline Sq & 44.4 & $\mu \mathrm{m}$ \\
\hline Ssk & 0.0303 & \\
\hline Sku & 1.81 & \\
\hline Sp & 87.5 & $\mu \mathrm{m}$ \\
\hline Sv & 95.2 & $\mu \mathrm{m}$ \\
\hline Sz & 183 & $\mu \mathrm{m}$ \\
\hline Sa & 38.5 & $\mu \mathrm{m}$ \\
\hline
\end{tabular}
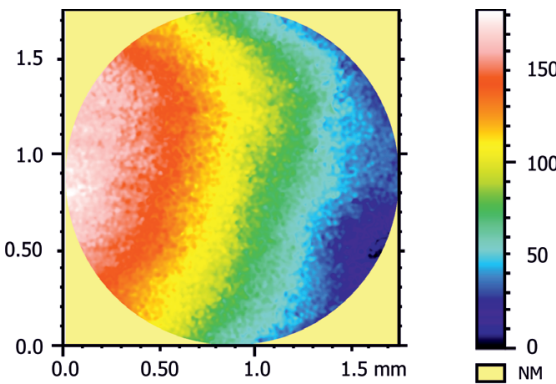
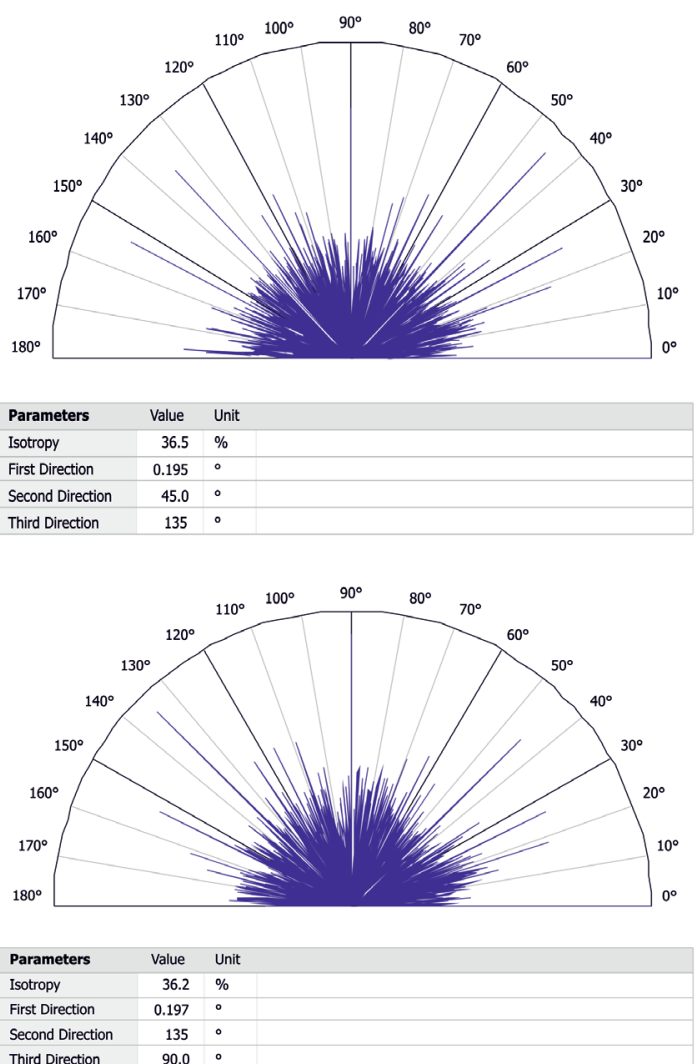

Fig. 3. Surface morphology characterization of 'maize 2' - statistic characteristics, 3D morphological views and polar graph with texture directions for: $\mathrm{A}$ - side ' $\mathrm{a}$ ', position $1, \mathrm{~B}$ - side ' $\mathrm{b}$ ', position 1 .

- a 3D surface morphology in contact area - describes circular height maps,

- a polar graph with texture directions.

The number of measured points in one measurement amounted to almost 15000000 points. The study indicates the values for the most significant texture directions found in the surface. Isotropic surfaces have isotropy values near $100 \%$; anisotropic surfaces presenting a main direction have values near $0 \%$. A schematic diagram of experimental arrangement is presented in Fig. 1.

For each side of maize grain with the moisture content of $11.1 \%$ and maize grain with the moisture content of $40.2 \%$, four measurement areas were chosen because of their potentially highest contact with other surfaces - other grain or grains, surface on which the grain is transported (such as steel), or the inner surface of the container/mixer. These places of grains are convex, thus also these zones are responsible for the contact surface.

\section{RESULTS AND DISCUSSION}

Figure 4 shows the contact area measurement of the maize grain surface parameters. Each of the maize grains was observed from two sides - from the 'top' - side ' $a$ ' and

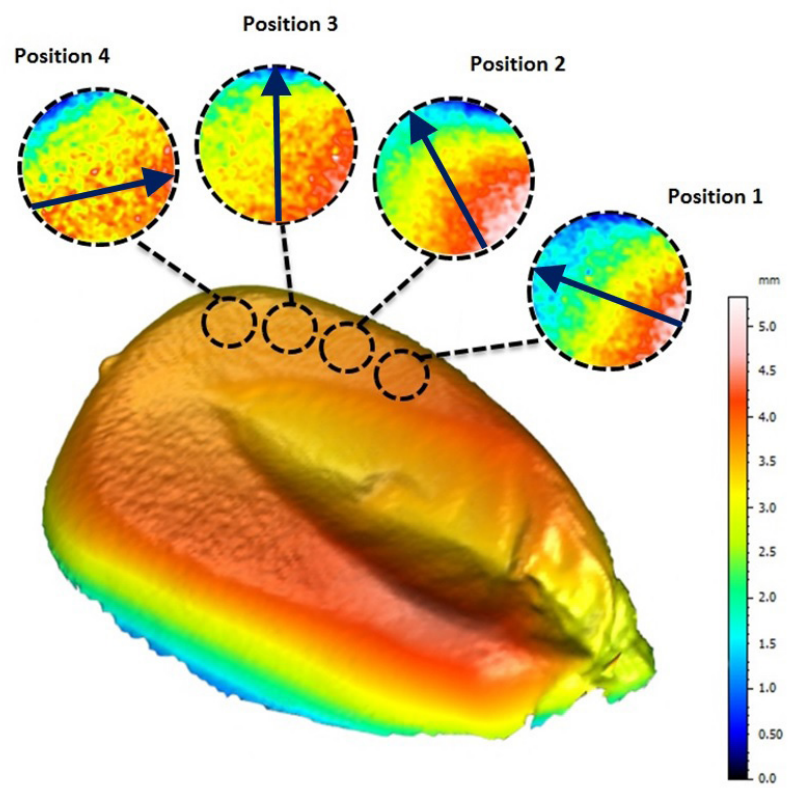

Fig. 4. Contact area measurement of the maize grain surface parameters with texture direction - side 'a', 'maize 1'. 
'bottom' - side 'b'. Fig. 4 shows 'side a' of maize grain ' 1 ' (with lower moisture, which was involved in the mixing process) with marked four positions of microstructures obtained using the IFM scanner. For a single grain, eight observations in various positions (4 from the 'top' and 4 from the 'bottom') were performed. It is not possible to characterize the whole grain with selected roughness parameters (such as $S s k, S k u$ ) in a representative way due to the nature/characteristics of the surface (a different shape in different places of the grain). Therefore, it was necessary to select the major (four as mentioned above) surface areas of contact. Biological material, such as maize grain, has a different shape in different places. Figure 2A presents the surface morphology characterization of 'maize 1' for side ' $a$ ' in position 1 (as labelled in Fig. 4) statistic characteristics, the 3D morphological view, and the polar graph with texture directions. Figure 2B presents side ' $b$ ' of the same grain. All results of statistic characteristics such as $S q, S s k$, $S k u, S p, S v, S z$, and $S a$, as well as isotropy and the first direction are presented in Table 1.

Figure $3 \mathrm{~A}, \mathrm{~B}$ presents the characterization of the surface morphology of 'maize 2' for side ' $a$ ' and ' $b$ ' in position 1 - statistic characteristics, the 3D morphological view, and the polar graph with texture directions. All results of statistic characteristics such as $S q, S s k, S k u, S p, S v, S z$, and $S a$, as well as isotropy and the first direction are presented in Table 2.

The distribution of the values of the coefficient of parameter Ssk (surface asymmetry - skewness) and the coefficient of its inclination of the $S k u$ (kurtosis) parameter are presented in Fig. 5A,B. The values of these surface roughness parameters are strongly influenced by single elevations and depressions on the surface (Królczyk et al.,
2015). According to Bigerelle et al. (2013), the $S s k-S k u$ parameter pair demonstrates that each of these parameters can be used to characterize the properties of the surface topography according to their tribological functionality. From the tribological point of view, in contact of the surfaces, sharp peaks are first destroyed due to decohesion and rounded peaks due to adhesion (Niemczewska-Wójcik, 2011). In turn, the more surface defects on the surface, the higher the $S k u$ value (Niemczewska-Wójcik et al., 2014). By comprehensive analysis of the surface roughness parameters of cereal grains, certain dependencies between the grain surface and the course of the mixing process can be observed.

The analysis of the results of the experimental research for 'maize 1' presented in Fig. 5A revealed that the values of roughness parameters $S k u$ and $S s k$ are characterized by higher values, compared with the 'maize 2' grains (Fig. 5B). This trend is visible for both sides of the analyzed maize - side 'a' and side ' $b$ '. The Ssk parameter ie the surface skewness coefficient, provides information about the asymmetry of the surface. The $S s k$ parameter value indicates the predominance of peaks for $S s k>0$ or valley structures for $S s k<0$ on the surface. When the values of skewness $S s k$ are negative (Fig. 6), the values indicate that a majority of the material is localised near the peaks of the surface. In turn, the $S k u$ parameter demonstrates the presence of inordinately high peaks or deep valleys for $S k u>3$ on the analyzed surface or absence thereof on the surface for $S k u<3$ (Fig. 6).

For maize with the lowest moisture, Fig. 5A demonstrates the presence of high peaks or low valley structures for positions 3 and 4 for side ' $a$ ' and positions 2 and 3 for side ' $b$ '. The mean value of $S k u$ for side 'a' is 3.25 and for

T a b l e 1. Statistic characteristics of surface morphology 'maize 1'-11.1\%

\begin{tabular}{|c|c|c|c|c|c|c|c|c|c|c|}
\hline \multirow{3}{*}{$\begin{array}{l}\text { Height } \\
\text { parameter }\end{array}$} & \multicolumn{5}{|c|}{ Side 'a' } & \multicolumn{5}{|c|}{ Side 'b' } \\
\hline & \multicolumn{4}{|c|}{ Position } & \multirow{2}{*}{ Mean } & \multicolumn{4}{|c|}{ Position } & \multirow{2}{*}{ Mean } \\
\hline & 1 & 2 & 3 & 4 & & 1 & 2 & 3 & 4 & \\
\hline$S q(\mu \mathrm{m})$ & 36.30 & 44.70 & 28.00 & 21.80 & 32.70 & 74.40 & 56.60 & 67.90 & 67.60 & 66.66 \\
\hline Ssk & 0.25 & -0.32 & -0.83 & -0.99 & -0.47 & -0.07 & -1.97 & -1.00 & -0.25 & -0.82 \\
\hline Sku & 2.16 & 2.45 & 4.10 & 4.29 & 3.25 & 1.91 & 6.50 & 3.72 & 2.07 & 3.55 \\
\hline$S p(\mu \mathrm{m})$ & 91.70 & 95.4 & 81.10 & 65.50 & 83.43 & 143.00 & 61.40 & 120.00 & 124.00 & 112.10 \\
\hline$S v(\mu \mathrm{m})$ & 92.60 & 138.00 & 121.00 & 92.90 & 111.13 & 181.00 & 248.00 & 250.00 & 163.00 & 210.50 \\
\hline$S z(\mu \mathrm{m})$ & 184.00 & 233.00 & 202.00 & 158.00 & 194.25 & 325.00 & 310.00 & 370.00 & 287.00 & 323.00 \\
\hline$S a(\mu m)$ & 30.80 & 37.20 & 21.30 & 16.50 & 26.45 & 64.10 & 41.30 & 53.20 & 57.10 & 53.93 \\
\hline Isotropy (\%) & 43.20 & 41.20 & 35.10 & 40.40 & 39.98 & 44.60 & 34.30 & 30.30 & 45.80 & 38.75 \\
\hline $\begin{array}{l}\text { First } \\
\text { direction }\left(^{\circ}\right)\end{array}$ & 154.00 & 116.00 & 90.00 & 26.50 & & 45.00 & 90.00 & 0.16 & 0.14 & \\
\hline
\end{tabular}


T a b l e 2. Statistic characteristics of surface morphology "maize 2"- $40.2 \%$

\begin{tabular}{|c|c|c|c|c|c|c|c|c|c|c|}
\hline \multirow{3}{*}{$\begin{array}{l}\text { Height } \\
\text { parameter }\end{array}$} & \multicolumn{5}{|c|}{ Side 'a' } & \multicolumn{5}{|c|}{ Side 'b' } \\
\hline & \multicolumn{4}{|c|}{ Position } & \multirow{2}{*}{ Mean } & \multicolumn{4}{|c|}{ Position } & \multirow{2}{*}{ Mean } \\
\hline & 1 & 2 & 3 & 4 & & 1 & 2 & 3 & 4 & \\
\hline$S q(\mu \mathrm{m})$ & 43.90 & 21.80 & 38.20 & 38.80 & 35.68 & 44.40 & 14.60 & 25.30 & 57.10 & 35.35 \\
\hline Ssk & -0.11 & 0.60 & -0.66 & -0.33 & -0.12 & 0.03 & -0.26 & -0.21 & -0.10 & -0.14 \\
\hline Sku & 2.03 & 2.62 & 2.71 & 2.07 & 2.36 & 1.81 & 1.95 & 2.09 & 1.89 & 1.94 \\
\hline$S p(\mu \mathrm{m})$ & 86.70 & 69.2 & 75.90 & 71.00 & 75.70 & 87.50 & 31.40 & 50.70 & 111.00 & 70.15 \\
\hline$S v(\mu \mathrm{m})$ & 101.00 & 50.70 & 123.00 & 97.60 & 93.08 & 95.20 & 39.20 & 67.00 & 153.00 & 88.60 \\
\hline$S z(\mu \mathrm{m})$ & 188.00 & 120.00 & 198.00 & 169.00 & 168.75 & 183.00 & 70.70 & 118.00 & 264.00 & 158.93 \\
\hline$S a(\mu \mathrm{m})$ & 37.20 & 17.80 & 31.30 & 33.10 & 29.85 & 38.50 & 12.60 & 21.50 & 49.30 & 30.48 \\
\hline Isotropy (\%) & 36.50 & 40.20 & 31.00 & 40.60 & 37.08 & 36.20 & 45.90 & 35.80 & 34.20 & 38.03 \\
\hline $\begin{array}{l}\text { First } \\
\text { direction }\left(^{\circ}\right)\end{array}$ & 0.20 & 0.22 & 0.23 & 0.22 & & 0.20 & 0.19 & 0.19 & 0.26 & \\
\hline
\end{tabular}

side ' $b$ ' is 3.55 (Table 1). In turn, for maize grains with the higher moisture, the values of $S k u$ are lower than 3 and they are located in the range of 1.81-2.71 (Table 2). The mean value of $S k u$ for side ' $a$ ' is 2.36 and for side ' $b$ ' is 1.94. The Ssk parameter can be useful during monitoring of surface wear, while the $S k u$ parameter can be applied for determining peak errors on surfaces, which result in an increased value of contaminants in cereal granular mixture. Negative values of Ssk indicate that the surface is characterized by low valley structures; positive values represent sharp peaks on the surface, which in the process of mixing will be cut off (friction) by other grains. For maize grain with lower moisture, negative values of Ssk dominated, while for maize grain with higher moisture, explicitly negative values were observed. This demonstrates the presence of low valley structures on the surface. The surface wear causes an increase in the value of the Ssk parameter, which means that the valleys on the surface become deeper, and consequently, grains influenced by pressure caused by the weight of the mixture inside the mixer can be subject to cracking. According to Wiacek et al. (2011), the main features of biologically based materials, such as maize used in this research, which make them different from mineral materials, include a strong influence of moisture content on mechanical behaviour and high deformability of granules. These differences bring about certain peculiar behaviours and enforce adjustments of contact models and calculation techniques. Identification of the actual sizes, such as $S s k$ and $S k u$, provides the capacity to predict actual forces and pressures occurring in the bed. By analysing the research results presented in the charts and tables, it can be observed that there is a close relationship between the maize grain moisture content and the surface roughness parameters $S s k$ and $S k u$. Moreover, the values of the analyzed parameters Ssk and Sku, depending on the measurement point (positions $1-4$ ), are characterized by smaller discrepancies (scatter) for grains with the higher moisture content.

It is worth commenting on the results obtained for other roughness parameters such as $S q, S p, S v, S z$, and $S a$. For the maize grain with the lower moisture content, greater discrepancies are observed for side ' $a$ ' compared with side ' $b$ '. For side ' $b$ ', higher mean values are observed in all roughness parameters: $S q=66.66 \mu \mathrm{m}$ (side 'b') vs. $32.70 \mu \mathrm{m}$ (side 'a'); $S p=112.10 \mu \mathrm{m} v s .83 .43 \mu \mathrm{m} ; S v=210.50 \mu \mathrm{m}$ vs. $111.13 \mu \mathrm{m} ; S z=323.00 \mu \mathrm{m}$ vs. $S z=194.25 \mu \mathrm{m}$; and $S a=53.93 \mu \mathrm{m} v s . S a=26.45 \mu \mathrm{m}$. Moreover, the mean values of $S p, S v$, and $S z$ are relatively higher for the maize grain with the lower moisture content. Values for 'maize 2' are characterized by smaller discrepancies.

Analysis of the results of the first direction presented in Tables 1-2 showed that the grain with the moisture content of $11.1 \%$ is characterized by a variable direction of the surface structure. Such a direction is responsible for the rotations during the movements of grain. In the case of the maize with the moisture content of $40.2 \%$, one main direction of the structure can be observed over the entire surface. This is due to the fact that corn is a biological material and grows in the corn cob in a unidirectional way. This grain was collected and analyzed immediately after the harvest, and was not subjected to the process of drying, transport, storage, and mixing.

Interesting results were obtained for isotropy. The range:

- for 'maize 1' was: $35.1-43.2$ and $30.3-45.8 \%$ for side 'a' and ' $b$ ', respectively; 
A

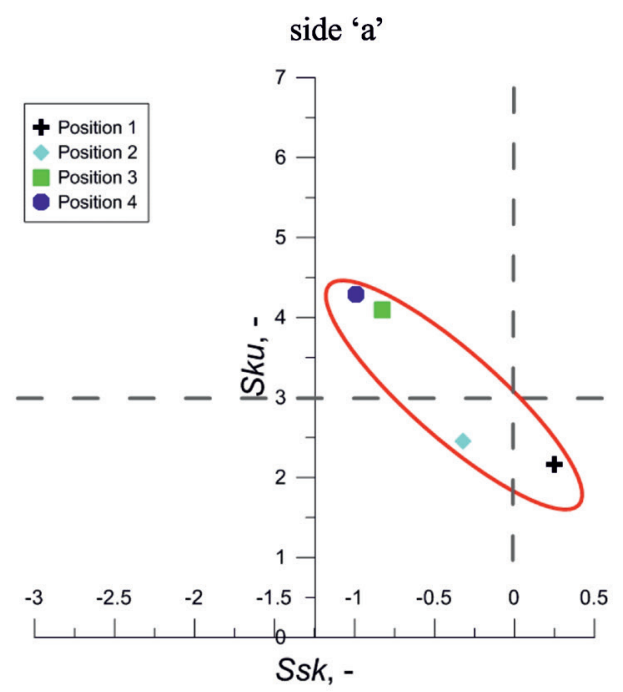

B

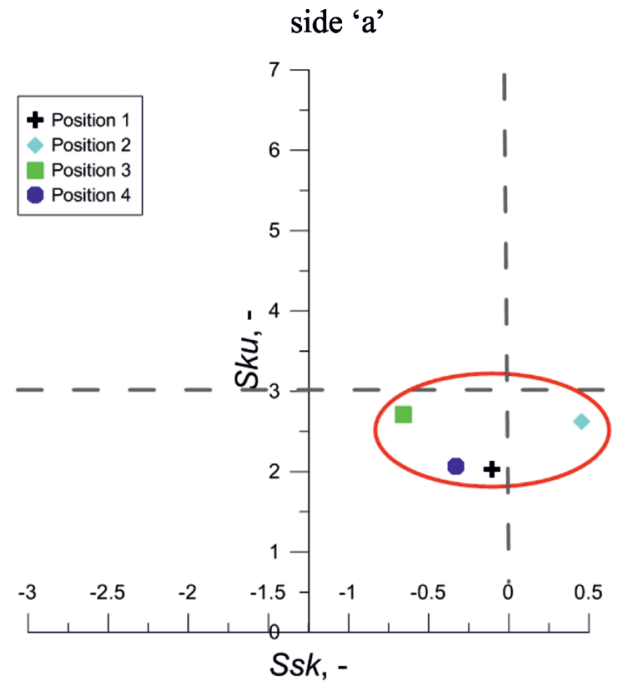

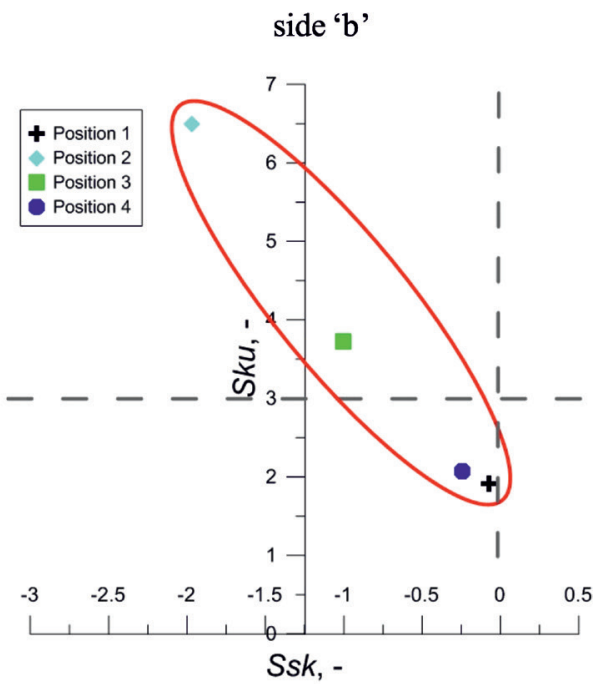

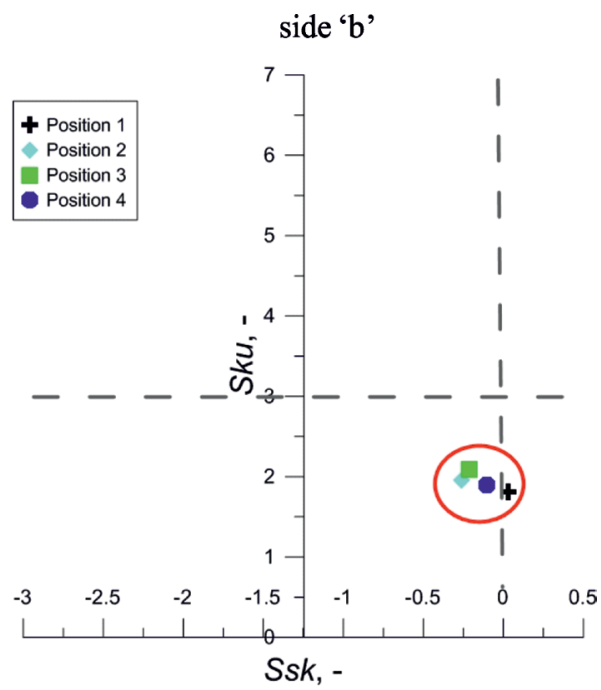

Fig. 5. The maps of kurtosis $(S k u)$ versus skewness $(S s k)$ for: A - 'maize 1' and B - 'maize 2' side 'a' and side 'b',

- while for 'maize 2' it amounted to 31.0-40.6 and 34.2$45.9 \%$ for side ' $a$ ' and ' $b$ ', respectively. This proves the

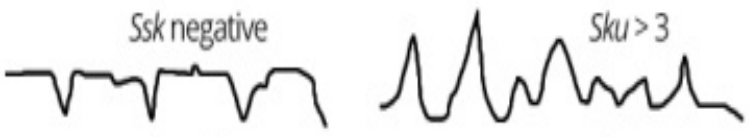

Ssk positive
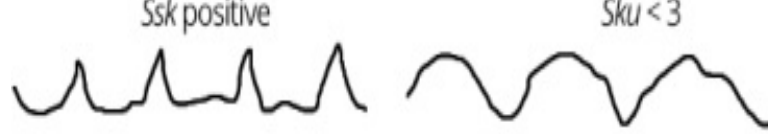

Fig. 6. Schematic representation of surfaces with different skewness (left) and kurtosis (right). existence of an anisotropic structure for maize grains (isotropy in the range from 30.3 to $45.9 \%$ ).

\section{CONCLUSIONS}

1. The new idea of analysis of the surface morphology using an optical 3D measurement provides a better understanding of the phenomenon and a description of the complexity of cereal grain biological systems. The surface morphology of cereal grains is the result of interactions of cooperating surfaces, which can be represented as threedimensional contact. 
2. The values of roughness parameters kurtosis and skewness are characterized by higher values for maize grains with lower moisture (11.1\%). Negative values dominated for maize grain with lower moisture $(11.1 \%)$, while for maize grain with higher moisture $(40.2 \%)$, only negative values were observed. This demonstrates the presence of low valley structures on the surface. The surface wear causes an increase in the value of the skewness parameter, which means that the valleys on the surface become deeper and, consequently, grains influenced by pressure caused by the weight of the mixture inside the mixer can be subject to cracking.

3. There is a close relationship between the maize grain moisture content and the surface roughness parameters - kurtosis, skewness, maximum peak height, maximum valley depth, maximum height of surface. The values of the analyzed parameters, depending on the measurement point (positions $1-4$ ), are characterized by smaller discrepancies for grains with the higher moisture content.

4 . The first direction of grain with the moisture content of $11.1 \%$ is characterized by a variable direction of the surface structure, while for the grain with the moisture content of $40.2 \%$, one main direction of the structure can be observed over the entire surface.

5. Maize grains have an anisotropic structure (isotropy in the range from 30.3 to $45.9 \%$ ).

\section{REFERENCES}

Bigerelle M., Najjar D., Mathia T., Iost A., Coorevits T., and Anselme K., 2013. An expert system to characterise the surfaces morphological properties according to their tribological functionalities: The relevance of a pair of roughness parameters. Tribology Int., 59, 190-202.

Blair D.L., Mueggenburg N.W., Marshall A.H., Jaeger H.M., and Nagel S.R., 2001. Force distributions in three-dimensional granular assemblies: Effects of packing order and interparticle friction. Physical Review, E, 63(4), 041304.

Boac J. M., Casada M. E., Maghirang R. G., and Harner III J. P., 2010. Material and interaction properties of selected grains and oilseeds for modeling discrete particles. Transactions of the ASABE, 53(4), 1201-1216.

Boss J., 1987. Solids Mixing Process. PWN Press, Warszawa Wrocław, Poland.

Bridgwater J., 2012. Mixing of powders and granular materials by mechanical means-A perspective. Particuology, 10, 4, 397-427.

Chaudhuri B., Mehrotra A., Muzzio F.J., and Tomassone M.S., 2006. Cohesive effects in powder mixing in a tumbling blender. Powder Technology, 165(2), 105-114.

Cleary P. W. and Sinnott M. D., 2008. Assessing mixing characteristics of particle-mixing and granulation devices. Particuology, 6(6), 419-444.

Doucet J., Bertrand F., and Chaouki J., 2008. Experimental characterization of the chaotic dynamics of cohesionless particles: application to a V-blender. Granular Matter, 10(2), 133-138.
Frączek J., Kaczorowski J., Ślipek Z., Horabik J., and Molenda M., 2003. The standardization of methods for measuring physical and mechanical properties of granular plant materials (in Polish). Acta Agrophysica, Rozprawy i Monografie, 92, 1-160.

Frączek J. and Ślipek Z., 2006. Models of vegetable granular structures (in Polish). Inżynieria Rolnicza, 10, 145-154.

Frączek J. and Wróbel M., 2003. Method for the defining of a contact surface between seeds (in Polish). Acta Agrophysica, 3(02), 519-529.

Horabik J. and Molenda M., 2002. Physical properties of bulk raw food. The outline of catalog (in Polish). Acta Agrophysica, 74, 1-90.

Królczyk J., 2013. Analysis of the amount of impurities received in the feed production process with recirculation of ingredients (in Polish). Inżynieria Rolnicza, 3(145), 149-157.

Królczyk J.B., 2014a. An attempt to predict quality changes in a ten-component granular system. Technical Gazette, 21(2), $255-261$

Królczyk J.B., 2014b. The use of cluster analysis method to describe the mixing process of the multi-element granular mixture. Transactions of FAMENA, 37(4), 43-54.

Królczyk G.M., Nieslony P., Królczyk J.B., Samardzic I., Legutko S., Hloch S., Barrans S., and Maruda R.W., 2015. Influence of argon pollution on the weld surface morphology. Measurement, 70, 203-213.

Królczyk J. and Tukiendorf M., 2005. Using the methods of geostatic function and Monte Carlo in estimating the randomness of distribution of a two-component granular mixture during the flow mixing. Electronic J. Polish Agricultural Universities, Series Agricultural Engineering, 8(4), http://www.ejpau.media.pl/volume8/issue4/art-78.html

Królczyk J. and Tukiendorf M., 2008. Research on the impact mass fractions of Multi-element granular structure on the mixing process. Int. Agrophysics, 22, 45-52.

Laurent B.F.C., Bridgwater J., and Parker D.J., 2002. Convection and segregation in a horizontal mixer. Powder Technology, 123(1), 9-18.

Mabille F. and Abecassis J., 2003. Parametric modelling of wheat grain morphology: a new perspective. J. Cereal Sci., 37, 43-53.

Mathia T.G., Pawlus P., and Wieczorowski M., 2011. Recent trends in surface metrology. Wear, 271(3-4), 494-508.

Mehta A., 2012. Granular Matter: an interdisciplinary approach. Springer Science Business Media, New York, Berlin, Heidelberg, London, Paris, Tokyo, Hong Kong, Barcelona, Budapest.

Molenda M., 2009. Expertise of mechanical properties of bulk agro materials and food powders. Methods of determination and forecast of trends standardization (in Polish). Available on-line: http://www.agengpol.pl/LinkClick.aspx?fileticket $=$ eopzElWGCjc\%3D\&tabid $=144$.

Niemczewska-Wójcik M., 2011. The influence of the surface geometric structure on the functionality of implants. Wear, 271, 596-603.

Niemczewska-Wójcik M., Gawlik J., and Sladek J., 2014. The measurement and analysis of surface geometric structure of ceramic femoral heads. Scanning, 36, 105-114. 
Pöschel T. and Schwager T., 2010. Computational Granular Dynamics: Models and Algorithms. Springer Science Business Media, Berlin, Heidelberg, New York.

Wiącek J. and Molenda M., 2011. Moisture-dependent physical properties of rapeseed-experimental and DEM modeling. Int. Agrophys., 25, 59-65.

Wiącek J., Molenda M., and Horabik J., 2011. Mechanical properties of granular agro-materials. Continuum and discrete approach. Acta Agrophysica, 1, 1-152.

Wieczorowski M., 2001. Spiral sampling as a fast way of data acquisition in surface topography. Int. J. Machine Tools. Manufacture, 41(13), 2017-2022.
Wojtkowski M., Pecen J., Horabik J., and Molenda M., 2010. Rapeseed impact against a flat surface: Physical testing and DEM simulation with two contact models. Powder Technology, 198(1), 61-68.

Wornyoh E.Y., Jasti V.K., and Higgs C.F., 2007. A review of dry particulate lubrication: powder and granular materials. J. Tribology, 129(2), 438-449.

Yang C., 2006. Density effect on mixing and segregation processes in a vibrated binary granular mixture. Powder Technology, 164(2) 65-74.

Zięba S., 2001. The algorithm of organization of biological systems. Agrophysics at the beginning of the XXI century (in Polish). Wydawnictwo Naukowe FRNA, 3, 21-22. 